Check for updates

1 The UK Health Alliance on Climate Change

Cite this as: $B M J 2021 ; 375: n 2787$ http://dx.doi.org/10.1136/bmj.n2787 Published: 12 November 2021

\title{
COP26 diary: at last, a dinner
}

\section{Richard Smith chair}

My only commitments of today are a meeting with an Indian friend and a dinner, but I become involved in the determination of the "health people" in the blue zone at $\mathrm{COP} 26$, perhaps 50-100 of us, to get Alok Sharma, the president of $\mathrm{COP} 26$, to receive the healthy prescription letter signed by health organisations representing 46 million health workers and brought from Geneva to Glasgow by cycling health workers. ${ }^{1}$

Sharma, I imagine, must be in a bunker somewhere in the innermost and most well guarded sanctum of COP26. I doubt he's eating a healthy diet, sleeping well, or exercising. He's more likely presiding over a disaster than a triumph and besieged by messages from people demanding the earth, the oceans, and the stars. It seems unlikely that he has actively rebuffed us, more likely no message of ours has ever reached him.

I suggest a strategy of getting Conservative MPs to talk to him as they will have more influence than any other group. Unfortunately, nobody knows any Conservative MPs. My next suggestion is to get college presidents to write to him, and we put this into action. My third option is to resort to the media, but this is the nuclear option and likely to be counterproductive.

Generally, things are not going well at COP26. The commitment to $\$ 100$ billion from rich to poor countries is not being met and is not enough anyway. Low-income countries feel betrayed. Current NDCs (Nationally Determined Contributions) will not keep us below a $2 \mathrm{C}$ increase let alone 1.5C. Lobbyists for fossil fuel companies are the single biggest contingent.

The narrative of everything being awful, but then coming right is not only the story of global negotiations and sports tournaments, but also most literature and fairy stories and so I'm not despondent yet. We must keep pushing.

After the daily plotting meeting of the health lobbyists, (Are we lobbyists? We don't think of ourselves that way, but I suppose we are. We are at least on the side of the angels, but maybe the fossil fuel lobbyists think so too.) I tour the pavilions. It's a tour of the world: Turkey, Colombia, Ghana, Bangladesh, the Benelux countries, Saudi Arabia, and so on. The European Union seems to have the biggest pavilion, but is mostly closed, confirming the anxieties of Brexiteers. The US pavilion seems modest. There are no Chinese or Russian pavilions, nor a British one.

The "geography" of COP26 is complex. The blue zone has been "handed over" to the United Nations, but its host is the UK government. Despite this being Glasgow, the Scottish government has a backroom role, although I understand that it set the covid rules for the conference, which seems sensible and reasonable in that hospitals in Scotland will have to respond to any outbreak.

I travel into central Glasgow to meet a friend of the Public Health Foundation of India and learn more about the many attacks it has experienced from government and anti-vaxxers from both the political left and right. Later I heard a Nigerian speak admiringly of how policy makers in high income countries listen to health campaigners and are interested in evidence. A British public health person pointed out that it wasn't all rosy in Britain by any means, but I think it right that craziness has less purchase in the UK than many other countries, although as I write the sentence I'm not sure.

To a dinner for health leaders attending $\mathrm{COP} 26$ at the Royal Glasgow College of Physicians and Surgeons. Parveen Kumar, professor of medicine and education and a central and much-loved figure in British and global medicine, talked of the seriousness of the threat to health from climate change and praised medical students for the actions they have been taking to counter climate changes. Nick Watts, chief sustainability officer for NHS England and a veteran of 14 COPs, remembered when he was one of only two health people at a COP and said that an age of concerted action on climate change and health is now beginning.

Sonia Roschnik, once the head of the NHS Sustainable Development Unit and now with Healthcare Without Harm, earned a round of applause when she talked about how we need to support low-income countries to create net-zero health systems. Malawi is one of the first countries to declare that it will make its health system net-zero, but compared with health systems in high income countries it must have negligible emissions of greenhouse gases. The trick for Malawi is surely not to try and build the high-carbon, expensive, complex, hospital-and-specialist-dominated, and ultimately unsustainable sickness systems of high income countries, but a true health system that is community-led and concentrates on public health, health promotion, prevention, and primary care. Colleagues from low and middle income countries and I once tried to think of how currently underdeveloped health systems could avoid copying the health systems of high-income countries and create something better. ${ }^{2}$ I fear, however, that the culture of modern medicine leads us to unsustainable excess just as our economies lead us to overconsumption and high emissions of greenhouse gases.

Competing interests: Richard Smith is the chair of the UKHACC and is former editor in chief of The BMI.

https://healthyclimateletter.net/ 
2 Cerqueira MT, Cravioto A, Dianis N, etalUnitedHealth, National Heart, Lung, and Blood Institute Centers of Excellence. Global response to non-communicable disease. BMI 2011;342:d3823. doi: 10.1136/bmi.d3823. pmid: 21724543 